\title{
VALOR PERCEBIDO PELOS CONSUMIDORES: UM ESTUDO EXPLORATÓRIO EM RELAÇÃO ÃS LOJAS ONDE REALIZAM COMPRAS DE ALIMENTOS
}

\author{
Paulo Henrique Nogueira Biscola' \\ Rubens da Costa Santos ${ }^{2}$
}

\begin{abstract}
Resumo
No Brasil, os varejos de grande escala estão perdendo espaço para os formatos menores como pequenos supermercados, feiras e padarias. Os consumidores buscam realizar suas compras em locais que diminuam o ônus e aumentem o bônus na realização das compras. Para compreensão desse fenômeno, formulou-se o problema de pesquisa: quais os ônus e bônus que os consumidores percebem existir na escolha de um determinado formato de loja para realizarem suas compras de alimentos? Uma revisão do conhecimento a respeito de valor percebido e de seus antecedentes foi feita. Em seguida uma pesquisa exploratória em profundidade com 51 donas-de-casa (26 de baixa renda e 25 de alta) foi conduzida em uma média cidade brasileira. Os resultados apontaram a preocupação das consumidoras com a questão do preço e do tempo de viagem (proximidade). Os valores de Holbrook (1999) também foram analisados, bem como os esforços e os riscos percebidos. Na conclusão são apresentadas as limitações e as sugestões para novas pesquisas.
\end{abstract}

Palavras-chave: Comportamento do Consumidor. Valor Percebido. Sacrifício Percebido. Risco Percebido. Atributos de Varejo de Alimentos.

\section{O CONSUMIDOR FINAL E O VAREJO ALIMENTÍCIO COM LOJAS NO BRASIL}

No Brasil observa-se um grande fluxo de consumidores no setor varejista de alimentos, onde se encontram instaladas grandes redes, competindo lado a lado com formatos menores de varejo pela preferência do consumidor.

\footnotetext{
' Mestre em Administração de Empresas pela EAESP/FGV. Analista de Pesquisa, Desenvolvimento e Inovação da Embrapa Gado de Corte. Endereço: Av. I de maio, 217, Jardim São Bento, Campo Grande, MS, CEP 79004-620. E-mail: pbiscola@gvmail.br. ${ }^{2} \mathrm{PhD}$ em Marketing pela University of Texas at Austin. Professor Doutor da Fundação Instituto Administração - FIA. Endereço: Rua Valson Lopes, I0I S I3, São Paulo, SP, CEP 05360-020. E-mail: rubensc@fia.com.br. Artigo recebido em: I 5/09/2006. Aceito em: 31/05/2007. Membro do Corpo Editorial Científico responsável pelo processo editorial: Martinho Isnard Ribeiro de Almeida.
} 
O perfil desse mercado varejista e os hábitos de consumo do brasileiro mudaram muito na década de 90 . Primeiramente, houve a concentração do mercado nas grandes redes e a entrada de concorrentes estrangeiros, como o português Sonae, a americana Wal-Mart e o holandês Royal Ahold. Depois, com o fim da inflação, o consumidor deixou de lado as grandes compras mensais e, com isso, o conceito de loja de vizinhança, com variedade de produtos e serviços, voltou a ter importância maior (CORREA, 2003). Ainda nessa época, a entrada em vigor do Código de Proteção e Defesa do Consumidor, em 1991, também auxiliou na mudança de hábitos de consumo, mostrando um cliente que passou a exigir mais seus direitos (PESQUISA, 2003).

Com isso surgiu o consumidor que compra em várias lojas, dando preferência, muitas vezes, àquela localizada perto de sua casa. Em 2004, a proporção de consumidores que freqüentavam uma única loja para realizar suas compras de alimentos foi de apenas $5 \%$, enquanto que os que freqüentavam três ou mais locais aumentou para 74\% (SUPERMERCADOS, 2005).

De acordo com pesquisas realizadas em 2003 (PESQUISA, 2003) e 2004 (CONSUMIDOR, 2004) com consumidores de supermercados, a localização refletida na proximidade dos varejos de alimentos com as residências dos consumidores era fator relevante para a escolha de um hiper/supermercado, sendo que esse atributo era relevante para todas as classes sociais. No fator da proximidade está intrínseca a questão do ônus de se deslocar grandes distâncias e gastar tempo adicional para isso.

O preço, um dos esforços mais amplamente estudado pela literatura de marketing, na pesquisa realizada pelo Latin Panel em 2002, foi mensurado pela existência de promoções e preços baixos e, a exemplo da localização, foi apontado como de alta relevância pelas três classes analisadas $(\mathrm{A} / \mathrm{B}, \mathrm{C}$ e D/E).

A qualidade dos produtos e o local para estacionar (uma conveniência), que se constituem em bônus de acordo com a presente pesquisa, tiveram relevância, conforme aumentava a renda dos entrevistados. $\mathrm{O}$ bom atendimento e a limpeza, apontados por aproximadamente $30 \%$ dos pesquisados, foram também relevantes.

O fator opção/variedade foi apontado em segundo lugar de importância para as classes A e B, mas perdeu um pouco de sua relevância quando a renda dos entrevistados diminuía. Ou seja, a baixa renda preferia abrir mão de variedade em detrimento de fatores como preço e localização.

Pelo que foi visto nesta introdução, existem evidências que o consumidor busca realizar suas compras em locais que diminuam seu ônus e aumentem seu bônus. Portanto, os diversos formatos varejistas devem adquirir conhecimento em relação ao que os seus consumidores percebem como sacrifício (ou seja, o ônus) e benefício (ou seja, o bônus), para poderem conceber estratégias e ações de marketing coerentes com as demandas existentes. 
Entender melhor os ônus e bônus que levam um consumidor a escolher um determinado local para efetuar suas compras subsidiará a criação de estratégias de marketing mais eficientes, tanto para os pequenos varejistas como para as grandes redes e outros supermercados.

Este estudo não é relevante apenas para uma perspectiva empresarial de estratégia de marketing, mas também para um planejamento urbano. Pois as autoridades municipais e as prefeituras de posse das informações a respeito das dificuldades e das facilidades para aquisição de alimentos estarão aptas a desenvolver um planejamento urbano de forma a proporcionar uma melhor distribuição e acesso à oferta dos produtos e serviços nas áreas da cidade onde a demanda se encontra, por meio de legislações específicas. Essa preocupação com a administração pública foi evidenciada em trabalhos como os de Samli e Uhr (1974) e, mais recentemente, de Jarrat (2000).

No meio acadêmico existem poucos trabalhos relacionando o valor percebido com a preferência por determinados estabelecimentos comerciais. Como exemplos de trabalhos nessa linha foram localizados os desenvolvidos por Sweeney, Soutar e Johnson (1999), Thang e Tan (2003), Moura (2005) e Biscola (2005). Sendo os dois primeiros internacionais e os dois últimos nacionais. Este artigo, portanto, visa contribuir para um melhor entendimento desse tema recente em um contexto brasileiro.

Para tanto, formula-se o seguinte problema de pesquisa: quais os ônus e bônus que levam os consumidores a escolherem um determinado formato de loja para realizarem suas compras de alimentos?

\section{VALOR PERCEBIDO E SEUS COMPONENTES}

$\mathrm{Na}$ maioria dos trabalhos que trata do tema de valor percebido a definição corrente é a de que valor é uma avaliação geral do consumidor da utilidade de um produto baseada em percepções do que é recebido e do que é dado. O que é recebido varia de um consumidor para outro, por exemplo: alguns preferirão volume, outros a alta qualidade, e outros, ainda, a conveniência; o que é dado também varia, por exemplo: alguns estão preocupados somente com o dinheiro gasto e outros com o tempo e o esforço (ZEITHAML, 1988).

Dessa forma valor percebido representa um trade-off entre componentes dados e recebidos mais relevantes (ZEITHAML, 1988). Algumas definições de valor percebido utilizadas a partir da década de 80 podem ser encontradas no Quadro 1.

O que é recebido pelo consumidor compõe os benefícios. Como exemplo disso podem ser apontados: (a) atributos intrínsecos perceptíveis (ZEITHAML, 1988); (b) atributos extrínsecos (ZEITHAML, 1988; TEAS; AGARWAL, 2000); e (c) qualidade percebida (MONROE; KRISHNAN, 1985; ZEITHAML, 1988; DODDS; MONROE; GREWAL, 1991; TEAS; AGARWAL, 2000). 
Já o que é dado pelo consumidor é denominado como sacrifício, sendo composto por: (a) esforços monetários e não-monetários (MURPHY; ENIS, 1986; LIMA FILHO, 1999) e (b) riscos percebidos (SWEENEY; SOUTAR; JOHNSON, 1999; AGARWAL; TEAS, 2001; SNOJ; KORDA; MUMEL, 2004).

\begin{tabular}{|l|l|}
\hline \multicolumn{1}{|c|}{ Definições de valor percebido pelo consumidor } & \multicolumn{1}{|c|}{ Suporte Teórico } \\
\hline $\begin{array}{l}\text { A avaliação total do consumidor da utilidade de um produto } \\
\text { baseada na percepção do que é recebido e do que é dado }\end{array}$ & $\begin{array}{l}\text { Zeithaml, 1988; Sinha } \\
\text { e DeSarbo, 1998; } \\
\text { Sweeney et al., 1999 }\end{array}$ \\
\hline $\begin{array}{l}\text { Proporção de benefícios percebidos relativos aos sacrifícios } \\
\text { percebidos }\end{array}$ & $\begin{array}{l}\text { Monroe, 1991; Dodds } \\
\text { et al., 1991 }\end{array}$ \\
\hline $\begin{array}{l}\text { Valor de um produto/serviço pode ser entendido como sendo a } \\
\text { satisfação ou ganhos totais que um determinado cliente percebe } \\
\text { existir e recebe com a utilização efetiva do item adquirido. }\end{array}$ & Santos, 1997 \\
\hline $\begin{array}{l}\text { A avaliação do consumidor do valor que foi criado para ele pelo } \\
\text { fornecedor dados os trade-offs entre todos os benefícios e sac- } \\
\text { rifícios relevantes em uma situação de uso específica. }\end{array}$ & Flint et al., 1997; \\
\hline $\begin{array}{l}\text { Experiência de preferência relativista interativa que se refere à } \\
\text { avaliação de algum objeto por um sujeito. }\end{array}$ & Holbrook, 1999 \\
\hline $\begin{array}{l}\text { Valor do produto para um consumidor é criado quando os } \\
\text { benefícios que um consumidor adquire com um produto são } \\
\text { maiores do que os custos de longo-prazo que um consumidor } \\
\text { espera ter com esse produto }\end{array}$ & Slater e Narver, 2000 \\
\hline $\begin{array}{l}\text { Valor percebido é o resultado percebido do trade-off do conjunto } \\
\text { de componentes técnicos, funcionais, temporais e espaciais de } \\
\text { benefício e sacrifício }\end{array}$ & Heinonen, 2004 \\
\hline
\end{tabular}

Quadro 1: Definições de valor percebido pelo consumidor.

Fonte: Adaptado de Snoj, Korda e Mumel (2004, p. 158).

O trade-off entre qualidade (como benefício) e preço (como benefício e sacrifício) é o mais utilizado na literatura de valor percebido. Como trabalhos que utilizaram essa definição ou parte dela podem ser citados: Monroe e Krishnan (1985), Zeithaml (1988), Dodds, Monroe e Grewal (1991) e Sweeney, Soutar e Johnson (1999).

Para existir uma percepção positiva de valor, basta que a utilidade inferida da percepção de qualidade (um exemplo de benefício) seja maior do que a utilidade sacrificada. Com outras variáveis se mantendo estáveis, quanto mais positiva a percepção de valor dos compradores, maior será sua disposição para efetuar a compra (MONROE; KRISHNAN, 1985). Logo, existem três maneiras das empresas aumentarem o valor percebido de seus produtos/serviços e/ou da sua própria empresa: (a) por meio de um aumento dos benefícios da sua oferta e diminuição dos sacrifícios 
percebidos pelo consumidor; (b) por meio de aumento de benefícios somente; ou (c) por meio de diminuição de sacrifícios somente.

Em trabalhos mais recentes foram incluídos outros atributos além da qualidade e do preço, com o intuito de aumentar a utilidade do construto de valor percebido. Como atributos extrínsecos podem ser citados: marca, nome da loja e país de origem (TEAS; AGARWAL, 2000; AGARWAL; TEAS, 2001) e como os de nível alto de abstração relevante pode ser citado o risco percebido (SWEENEY; SOUTAR; JOHNSON, 1999; SNOJ; KORDA; MUMEL, 2004).

Além dos estudos que consideram o valor percebido como um trade-off entre o que é dado e recebido existe o trabalho de Holbrook (1999), no qual o autor considerou valor como um benefício sem, no entanto, vinculá-lo a um sacrifício.

\subsection{Valores de Holbrook (1999)}

Holbrook (1999) propôs uma taxonomia em que cada célula representa um tipo distinto de valor na experiência de consumo, sendo eles: eficiência, excelência, status, estima, entretenimento, estética, ética e espiritualidade.

A eficiência envolve valores extrínsecos que resultam do uso ativo de um produto ou experiência de consumo como um meio para atingir um objetivo auto-orientado. Alguns exemplos incluem objetos como chaves, lenços de papel e moedas. Geralmente a eficiência é mensurada como a razão de entradas e saídas. Um exemplo dessa razão é a conveniência para os consumidores que têm o tempo como um denominador que representa uma entrada (input) chave (HOLBROOK, 1999).

A excelência é uma apreciação reativa de algum objeto ou habilidade potencial de experiência para servir como uma maneira extrínseca para algum fim pessoal autoorientado, ou seja, alguém admira um objeto ou valoriza alguma experiência por sua capacidade de atingir um objetivo ou desempenhar alguma função. Como exemplo tem-se a qualidade, que surge como um tipo principal de valor quando um produto é admirado por sua capacidade para atingir algum desejo auto-orientado, mas atingindo sem realmente utilizar isso para esse propósito (reativo) (HOLBROOK, 1999).

O status diz respeito à manipulação ativa do comportamento de consumo próprio de alguém como um meio extrínseco em busca de um fim orientado para outros com intuito de atingir uma resposta favorável de outra pessoa. Em outras palavras, as pessoas consomem para comunicar sobre si para outros de maneira que isso contribua para seu sucesso, por exemplo, alguém que queira um emprego poderá escolher uma roupa para impressionar o entrevistador da empresa em que deseja trabalhar (HOLBROOK, 1999).

Estima seria a parte reativa e equivalente ao status, que resulta de um domínio passivo das posses encarado como um meio para construir uma reputação de alguém 
com outros. Como exemplos são observados traços de personalidade como o materialismo. A auto-estima também está classificada nesse tipo de valor, em que o outro é o próprio indivíduo, o "eu interior" (HOLBROOK, 1999).

O entretenimento envolve divertir-se e, dessa maneira, caracteriza o lado intrinsecamente motivado da distinção entre trabalho e lazer, ou entre eficiência e entretenimento. Exemplo: jogar futebol sábado à tarde com os filhos é uma diversão para alguns, enquanto que jogar futebol e integrar a equipe de um time e jogar no Estádio do Maracanã sábado à tarde é um trabalho para outros (HOLBROOK, 1999).

No lado reativo do entretenimento está a estética, que se refere a uma apreciação de alguma experiência de consumo valorizada intrinsecamente como um fim autoorientado em si mesmo. Como um exemplo tem-se a beleza, que depende de uma perspectiva auto-orientada e é reativa. O valor estético ou a beleza são autojustificados, lúdicos ou autotélicos, sem considerar qualquer objetivo prático futuro que possa servir como meio para qualquer outro fim (HOLBROOK, 1999).

As características ativas e orientadas para outros da ética envolvem fazer algo para o bem de alguém, ou seja, sabendo como algo poderia afetá-los positivamente. Logo essas experiências de consumo são valorizadas para o próprio bem da pessoa ou da sociedade como um fim em si mesmo. Exemplos: virtude é a tendência de o indivíduo ser a favor de ações que sigam leis, que obedeçam a regras ou preencham obrigações. Quando o correto alinha-se com o bom, ocorre justiça, situação em que as leis que governam a sociedade tendem a produzir conseqüências benéficas. E quando a natureza de uma pessoa corresponde com o bom, existe a moralidade, tendência do caráter de uma pessoa trabalhar a favor de resultados que aumentem o bem-estar de outros (HOLBROOK, 1999).

Como um equivalente mais reativo da ética, a espiritualidade implica em uma aceitação, adoção, apreciação, admiração ou adoração motivada intrinsecamente de um outro. Esse "outro" pode ser um poder divino, alguma força cósmica ou uma entidade mística. Como exemplos de espiritualidade têm-se a fé, o êxtase, o sagrado e o mágico (HOLBROOK, 1999).

\subsection{Sacrifício Percebido}

Não deve ser considerado apenas o que é dado ao consumidor; ao invés disso a empresa deve concentrar-se no sacrifício que o consumidor tem que fazer para adquirir um determinado produto ou serviço (RAVALD; GRÖNROOS, 1996). A esse respeito Monroe (1991) argumentou que consumidores valorizam mais uma redução em custos do que um aumento correspondente nos benefícios.

O sacrifício percebido inclui aspectos monetários e não monetários, sendo composto por duas dimensões denominadas esforço e risco (MURPHY; ENIS, 1986). As dimensões do sacrifício podem ser mais bem observadas no Quadro 2. 


\begin{tabular}{|l|l|l|}
\hline \multirow{2}{*}{ Aspectos } & \multicolumn{2}{|c|}{ Dimensões } \\
\cline { 2 - 3 } Monetário & \multicolumn{1}{|c|}{ Esforço } & \multicolumn{1}{c|}{ Risco } \\
\hline \multirow{4}{*}{ Não- Monheiro } & Financeiro \\
\cline { 2 - 3 } & Crédito & \\
\cline { 2 - 3 } & Negociação & \\
\hline & Tempo de Viagem & Social \\
\cline { 2 - 3 } & Tempo de Compra & Psicológico \\
\cline { 2 - 3 } & Tempo de Espera & Físico \\
\cline { 2 - 3 } & Tempo de Performance & Funcional (Performance) \\
\cline { 2 - 3 } & Tempo de Monitoramento & Tempo \\
\hline
\end{tabular}

Quadro 2: Dimensões de Sacrifício Percebido.

Fonte: Adaptado de Murphy e Enis (1986 p. 31).

O esforço é definido como uma quantidade objetiva de dinheiro e tempo para comprar um produto, ou seja, esforço pode ser mensurado em termos quantificáveis como unidades monetárias e de tempo (MURPHY; ENIS, 1986). O esforço pode ter um aspecto monetário (dinheiro ou preço, crédito ou negociação) ou não monetário (tempos: de viagem, de compra, de espera, performance e monitoramento).

O não-monetário de tempo foi identificado como um custo de consumo na década de 60 em trabalhos como os de Downs (1961) e Bender (1964). O tempo pode ser classificado em: de viagem, de compra, de espera, de performance e de monitoramento.

O tempo de viagem é definido como o tempo que um consumidor gasta para chegar a uma loja ou ao local onde se encontra o vendedor (CHERLOW, 1981). Os consumidores fazem trade-offs entre as localizações das lojas e economia de custos. A conveniência da localização é crucial para varejistas e diversos prestadores de serviços. Por outro lado, lojas com preços mais baixos, por causa de sua localização inconveniente apelam para consumidores dispostos a trocar tempo de viagem por economia no preço.

O tempo de compra é o tempo gasto por um comprador para procurar e avaliar um produto (BERRY, 1979). Como mecanismos usados para reduzir o tempo de compra podem-se citar as consultas com membros da família e amigos e a busca de informações na Internet a respeito de produtos.

O tempo de espera é o tempo gasto por um comprador para pagar por suas mercadorias e sair da loja, bem como esperar: por um vendedor, para ser atendido em uma empresa de serviços, ou por produtos pedidos. A oferta aos consumidores 
de serviço rápido (como, por exemplo, as cadeias de fast food) é um reconhecimento de que o tempo de espera é importante para uma grande parte dos consumidores (MURPHY; ENIS, 1986). Como exemplos de tempo de espera podem ser citados o tempo para que o produto ou serviço chegue até o consumidor, o que é evidenciado principalmente em casos de empresas que trabalham com entregas rápidas (delivery), ou compras feitas em lojas virtuais ou, ainda, a espera de prestadores de serviços que vão até as casas, como os personal trainers.

Os tempos de performance e de monitoramento foram estudados por Fox (1980). Segundo o autor, o tempo de performance foi definido como o tempo gasto para usar um produto ou realizar alguma ação e pode ser igualado ao tempo de consumo.

Já o tempo de monitoramento é o tempo gasto por alguém para se lembrar de realizar uma determinada ação. Indivíduos constantemente se esquecem de comprar um produto ou serviço, como agendar ou confirmar um horário no dentista. Produtos que economizam tempo facilitando o seu consumo e anúncios para lembrança apelam diretamente para tempos de performance e de monitoramento, respectivamente.

Além dos esforços existe a teoria de risco percebido em comportamento do consumidor, que teve seu início nos anos 60 na Harvard University a partir de proposta feita por Raymond Bauer (1960). O autor propôs que consumidores não maximizam utilidade como sugerido pelos economistas, mas minimizam riscos associados com suas escolhas (SHETH; GARDNER; GARRETT, 1988).

Esses riscos a serem diminuídos em favor de um aumento do valor percebido fazem parte do sacrifício. E, de acordo com Stone e Gronhaug (1993), o risco percebido foi definido como a expectativa subjetiva de uma perda. Em outras palavras, Roselius (1971) afirmou que risco é uma estimação subjetiva associada às conseqüências possíveis de decisões erradas tomadas por consumidores, uma possibilidade de que o produto não oferecerá todos os benefícios esperados.

Jacoby e Kaplan (1972) definiram os tipos de risco como sendo: a) Financeiros: risco no qual o consumidor está perdendo seu dinheiro, porque o produto não satisfaz suas expectativas e no qual, ao invés de um consumidor ter mais benefícios, investe mais dinheiro para adquirir um produto; b) Psicológico: risco de escolher um produto errado, o que pode ter efeito negativo no ego de um consumidor; c) Físico: risco de o consumidor prejudicar a si mesmo ou a outros quando se utiliza de um produto; e d) Social: risco no qual, pela escolha de um produto, o status do consumidor irá mudar entre seus amigos e/ou sua família.

Além desses tipos de riscos existe o risco de tempo, no qual o tempo gasto na procura de um produto será perdido se o mesmo não tiver um desempenho de acordo com a expectativa dos consumidores (SNOJ; KORDA; MUMEL, 2004), e o risco de performance, que é definido como a perda incorrida quando uma marca ou produto não tem o desempenho (performance) esperado (HORTON, 1976). 
A percepção geral de risco pelo consumidor pode ser formada por uma ou mais dessas fontes de risco, que podem atuar individualmente ou em conjunto (CAMPBELL; GOODSTEIN, 2001).

\section{METODOLOGIA}

Como constatado anteriormente, a literatura fornece informações a respeito dos atributos considerados pelo consumidor com relação aos supermercados, mas não aos outros tipos de formatos varejistas encontrados no Brasil. Além disso, os esforços não monetários de tempo e os riscos percebidos ainda não foram explorados em trabalhos realizados no contexto brasileiro.

Portanto, é recomendável realizar uma pesquisa qualitativa com os consumidores, anteriormente às futuras pesquisas quantitativas que não estão presentes no escopo deste trabalho.

Dessa forma, a pesquisa exploratória (MALHOTRA, 2002) foi aqui utilizada para extrair informações dos consumidores com relação aos ônus e bônus (componentes do valor percebido) associados com as compras de alimentos em diferentes estabelecimentos.

Especificamente a entrevista em profundidade semi-estruturada foi usada considerando-se que as pessoas poderiam ficar constrangidas em falar a respeito desse assunto diante de um grupo, optou-se então pela entrevista individual (MALHOTRA, 2002).

Como foi relatado na introdução deste trabalho, o varejo de alimentos possui grande quantidade de consumidores que diversificam suas compras entre os diferentes formatos de lojas presentes no país, o que justificou a escolha desse setor. Os formatos escolhidos, presentes no Brasil, foram os propostos por BOOZ ALLEN HAMILTON (2003): (a) comércio de larga escala (hipermercados, grandes supermercados e atacadistas); (b) pequenos supermercados; (c) tradicionais (mercearias e mercadinhos); (d) formatos de rua (feira livre); e (e) especialistas na categoria (açougue, sacolão e padaria).

O primeiro recorte desta pesquisa foi em relação aos tipos de produtos pesquisados (alimentos), os quais se classificam, segundo mesmo estudo realizado pela BOOZ ALLEN HAMILTON (2003), em: (a) embalados e (b) perecíveis e, nessas categorias, em: (a) básicos, (b) secundários; e (c) de luxo.

O segundo recorte adotado na pesquisa é o foco no momento da compra dos produtos alimentícios, sendo que não são avaliados os ônus e bônus com relação ao que decorre depois do ato de compra, como por exemplo, os momentos de preparação e consumo propriamente dito do produto. 
A pesquisa foi realizada na cidade de Campo Grande (MS), média capital brasileira localizada na região Centro-Oeste do Brasil, por ser uma localidade que apresenta as características necessárias para este estudo, ou seja, possuí todos os formatos varejistas presentes no país em seu território.

Foram realizados nos primeiros dez dias do mês de outubro de 2005 pré-testes do questionário com seis pessoas, sendo três de cada grupo de classe social. Esses pré-testes tiveram o intuito de auxiliar no aprimoramento da formulação das questões e do instrumento de coleta de dados, para assegurar que efetivamente captasse os ônus e bônus com questões que representassem os tópicos vistos na revisão do conhecimento sobre valor percebido e aqueles relativos às características das compras efetuadas em cada local (tipos de alimentos adquiridos, tamanho da compra e freqüência de compra). Esses cuidados respeitam as recomendações feitas por Churchill (1995). Também foi testada a capacidade dos entrevistados em responder às questões de acordo com seu grau de escolaridade.

Os entrevistados foram divididos de acordo com suas características socioeconômicas. A amostra foi composta por 51 pessoas, sendo que 25 das classes A e B e 26 das classes C, D e E. As entrevistas ocorreram durante os meses de outubro e novembro de 2005.

A unidade respondente, como nos estudos analisados anteriormente a exemplo daquele elaborado por Lima Filho (1999), neste estudo, foi a dona-de-casa. Levouse em consideração também a escolaridade das respondentes que, para efeito de recorte deste estudo, deveria corresponder ou ser superior à conclusão da $4^{\mathrm{a}}$ série do ensino fundamental e o fato de serem responsáveis na residência por compras freqüentes de alimentos.

As entrevistadas foram abordadas inicialmente por meio de contato telefônico, quando foi feito o convite para participarem do estudo e, havendo concordância e agendadas as entrevistas, elas eram efetuadas na própria residência da entrevistada, quando possível, para deixá-las mais à vontade.

\section{RESULTADOS E DISCUSSÃO}

Os conceitos de ônus e bônus se cruzam com o tema valor percebido, pois o que é considerado um sacrifício ou benefício por essa teoria, em determinada situação pode ser tanto um ônus quanto um bônus. Por exemplo, um esforço de preço pode ser um bônus quando for baixo ou um ônus quando for alto. $\mathrm{O}$ mesmo ocorre com a qualidade percebida, que ser for alta é um bônus, e se for baixa, um ônus.

Neste trabalho, a classificação utilizada para os atributos percebidos foi a de ônus e bônus, em conjunto com a teoria de valor percebido e seus antecedentes, por 
ser considerada a forma mais compreensível de demonstrar os sentimentos e opiniões das compradoras de alimentos entrevistadas.

Os resultados apontaram a grande preocupação das consumidoras entrevistadas com a questão do preço e da proximidade, os quais são considerados como dois esforços pela literatura.

O preço, como foi falado anteriormente já vinha sendo amplamente estudado, mas a proximidade (tempo de viagem) não está presente em muitos dos trabalhos analisados. Esse atributo deve ser levado em consideração, principalmente em um país como o Brasil, que é marcado pela grande desigualdade social. Portanto, como relatado na literatura e na pesquisa empreendida, a baixa renda tem dificuldades para ter acesso a determinados tipos de formatos, em especial os hipermercados e supermercados, fato que já havia sido apontado por Fox, Montgomery e Lodish (2004).

Cabe, assim, às grandes redes a descoberta de maneiras de oferecer acesso à baixa renda se tiverem interesse nesse público que, em conjunto, possui alto poder de compra (PRAHALAD, 2005).

A eficiência (HOLBROOK, 1999), representada pela variedade, é um fator procurado nas lojas. As entrevistadas de classe alta são mais exigentes nesse aspecto. A excelência (qualidade) é medida por meio de aparência e frescor dos produtos e pelo atendimento que é prestado aos clientes.

Em relação ao status (HOLBROOK, 1999), as consumidoras entrevistadas revelaram que não realizam suas compras preocupadas ou baseadas nas opiniões de outras pessoas, mas demonstram autoconfiança e busca de satisfação própria.

A estima (HOLBROOK, 1999) é representada pelo fato de as entrevistadas considerarem alguma loja como seu local de compra. Estava presente no discurso de algumas consumidoras o fato de ter afinidade maior com determinadas lojas onde realizavam compras.

A dimensão de entretenimento (HOLBROOK, 1999) envolve a diversão percebida no local de compra, muito presente nos relatos das consumidoras de baixa renda entrevistadas, quando elas freqüentam a feira e têm uma sensação de liberdade e alegria, como em um passeio. De uma forma mais comedida, ocorre o mesmo fenômeno com o grupo de alta renda entrevistado na pesquisa, ao relatar as experiências de compras nos hipermercados e supermercados que oferecem café da manhã ou pianistas que tocam música nos finais de semana, além de ser um local para encontro com outras pessoas. Essas promoções de café da manhã e sorteio de brindes são consideradas idéias interessantes para melhorar o ambiente da loja (BLOOM, 2005).

A estética foi evidenciada na análise da aparência e da atmosfera (ambiente) das lojas por parte das consumidoras desta amostra, que, em sua maioria, as avaliaram como possuidoras de boa aparência, com exceção dos casos em que as lojas eram consideradas muito cheias, mal organizadas e tumultuadas. 
A questão ética (HOLBROOK, 1999) teve como resposta de diversas entrevistadas que, se os locais onde realizam suas compras não seguirem as leis, elas continuam comprando, pois, entre suas crenças, acreditam que se a loja não seguir a lei, elas não fazem parte disso, portanto, não haverá problema algum em continuar comprando no local. Isso vem ao encontro dos resultados encontrados por Urdan e Zuñiga (2001) em estudo realizado no Brasil, em que os consumidores consideraram ser importante o comportamento ético das empresas, mas, nem por isso, estariam dispostos a escolher seus produtos e serviços baseados nesse atributo. A presença de portadores de deficiência trabalhando nas lojas foi considerada uma questão de ética das empresas. Existe outra crença de que as empresas maiores seguem as leis, pois são mais fiscalizadas.

A questão da espiritualidade (HOLBROOK, 1999), que é mais difícil de ser percebida, tem alguns exemplos em relação ao fato de as donas-de-casa admirarem uma loja com base em fatores como a variedade e quantidade, o preço, a história de vida dos donos e o trabalho deles visto no dia-a-dia.

Os esforços monetários (MURPHY; ENIS, 1986) presentes nas duas classes são representados pela procura de preços baixos, na qual a busca por promoções é evidenciada, e pela oferta de formas de pagamento alternativas, como cartões do estabelecimento (que oferecem maiores prazos) e a compra a prazo informal (compra fiada).

Os tempos também foram considerados pelas entrevistadas das duas classes, sendo que entre eles o mais destacado foi o tempo de espera nos estabelecimentos como ocorre em filas de caixa e em seções específicas como na padaria e açougues (MURPHY; ENIS, 1986).

Como maneiras para redução desse tempo, Grewal (2003) sugeriu: (a) a contratação de mais funcionários, (b) investimento em tecnologia; ou (c) redução da percepção de espera sem reduzir necessariamente o tempo.

O tempo de compra (BERRY, 1979) também é citado com destaque para a mudança dos locais dos produtos dentro das lojas, o que pode ser uma estratégia interessante do ponto de vista do varejista que retém o cliente por mais tempo em sua loja. Mas, por outro lado, é percebido como um ônus e pode se tornar um fator importante para que o cliente deixe de freqüentar algumas lojas.

O tempo de viagem (CHERLOW, 1981), retratado pela proximidade ou distância, figura como um dos fatores mais importantes e causa para que as consumidoras desta amostra deixem de comprar em determinadas lojas.

Como riscos percebidos, semelhantes para as duas classes sociais, têm-se: risco de não encontrar promoções (financeiro) e risco de comprar alimento estragado e ter que gastar tempo para trocá-lo (tempo). Além desses riscos são encontrados outros (Quadro 3), os quais foram categorizados em: financeiro, funcional, físico, social, psicológico e tempo. 


\begin{tabular}{|c|c|}
\hline Riscos & Riscos citados pelas entrevistadas de alta e baixa renda \\
\hline Financeiro & $\begin{array}{l}\text { Risco de outra pessoa somar errado o valor a ser pago pelos produtos } \\
\text { (baixa renda). } \\
\text { Risco de comprar parcelado, pois, como faz compras todo mês, as par- } \\
\text { celas se acumulam (baixa renda). } \\
\text { Risco de achar produtos mais baratos depois (baixa renda). } \\
\text { Risco de comprar a mais (alta renda). } \\
\text { Risco de não encontrar as promoções (alta e baixa renda). }\end{array}$ \\
\hline Funcional & $\begin{array}{l}\text { Risco da loja não oferecer o produto que deseja (baixa renda). } \\
\text { Risco de trocar a marca do produto e arrepender-se depois por causa da } \\
\text { qualidade (baixa renda). } \\
\text { Risco de comprar um produto vencido (baixa renda). } \\
\text { Risco de perder o sistema de compra de carnes por encomenda (alta renda). } \\
\text { Risco de perder na qualidade dos produtos (alta renda). } \\
\text { Risco de ir a outros locais e não encontrar o que quer (alta renda). }\end{array}$ \\
\hline Físico & $\begin{array}{l}\text { Risco de a sujeira prejudicar a saúde da entrevistada ou de sua família (no } \\
\text { açougue) (baixa renda). } \\
\text { Risco de comprar alimentos estragados (baixa renda). } \\
\text { Risco de saúde em produtos como o frango (alta renda). }\end{array}$ \\
\hline Psicológico & $\begin{array}{l}\text { Risco de trocar de locais de compra e não alcançar o objetivo da troca } \\
\text { (baixa renda). } \\
\text { Risco de esquecer as compras no ônibus (baixa renda). } \\
\text { Risco de comprar alimento novo (desconhecido) em promoção (alta renda). } \\
\text { Risco de escolher alimento errado (alta renda). }\end{array}$ \\
\hline Social & $\begin{array}{l}\text { Risco que de que outra pessoa critique o local onde faz compras de ali- } \\
\text { mentos (alta renda). }\end{array}$ \\
\hline Tempo & $\begin{array}{l}\text { Risco de perder tempo (baixa renda). } \\
\text { Risco de comprar alimento estragado e ter que gastar tempo para trocá-lo } \\
\text { (alta e baixa renda) }\end{array}$ \\
\hline
\end{tabular}

Quadro 3: Riscos percebidos pelas entrevistadas de alta e baixa renda.

Fonte: Elaborado pelos autores.

O risco percebido é apontado pelas entrevistadas como uma barreira crucial que pode vir a privá-las da escolha de uma determinada loja, produto ou serviço. Na literatura de marketing, o risco foi conceituado envolvendo dois elementos: a incerteza e as conseqüências (CONCHAR et al., 2004). Cabe às empresas reduzirem as incertezas e promoverem conseqüências positivas aos seus consumidores.

Embora a pesquisa seja qualitativa, optou-se por desenvolver dois quadros (Quadro 4 e 5) com as características das compras, os ônus e os bônus mais freqüentes para os tipos de lojas estudados por grupos de classes sociais entrevistadas. Cabe salientar que esse é apenas um esboço de quais poderiam ser os fatores mais 
importantes em cada varejo, pois para validar tais proposições seria necessária uma pesquisa quantitativa com amostra adequada para tal fim.

\begin{tabular}{|c|c|c|c|c|}
\hline \multirow{2}{*}{\multicolumn{2}{|c|}{ Formatos }} & \multirow{2}{*}{$\begin{array}{c}\text { Característica } \\
\text { da compra }\end{array}$} & \multicolumn{2}{|c|}{ Atributos mais freqüentes } \\
\hline & & & Ônus & Bônus \\
\hline \multicolumn{2}{|c|}{ Hipermercados } & $\begin{array}{l}\text { Semanal/Mensal. Bási- } \\
\text { cos e promoções (FLV) }\end{array}$ & $\begin{array}{l}\text { Distância. Fila. } \\
\text { Mudança de produ- } \\
\text { tos do lugar. }\end{array}$ & $\begin{array}{l}\text { Variedade. Qualida- } \\
\text { de. Aparência. }\end{array}$ \\
\hline \multicolumn{2}{|c|}{$\begin{array}{l}\text { Supermercados } \\
\text { de bairro }\end{array}$} & Semanal. Básicos. & $\begin{array}{l}\text { Distância. Dificul- } \\
\text { dade para ir. }\end{array}$ & $\begin{array}{l}\text { Preço baixo. Pro- } \\
\text { moções. Aparência. } \\
\text { Variedade. }\end{array}$ \\
\hline \multicolumn{2}{|c|}{ Atacados } & Mensal. Básicos. & $\begin{array}{l}\text { Filas grandes. Fal- } \\
\text { ta de sacola. }\end{array}$ & Preço baixo. \\
\hline \multicolumn{2}{|c|}{$\begin{array}{c}\text { Pequenos } \\
\text { supermercados }\end{array}$} & Semanal. FLV e carne & Aparência. Fila. & $\begin{array}{l}\text { Preço baixo. Proximi- } \\
\text { dade. Atendimento. }\end{array}$ \\
\hline \multicolumn{2}{|c|}{ Tradicionais } & $\begin{array}{l}\text { Compra de conveniên- } \\
\text { cia, esporádica e em } \\
\text { pequenas quantidades. }\end{array}$ & $\begin{array}{l}\text { Pequena variedade } \\
\text { e espaço. Preço } \\
\text { alto. Não aceitação } \\
\text { de outras formas } \\
\text { de pagamento. }\end{array}$ & $\begin{array}{l}\text { Conveniência. Qua- } \\
\text { lidade dos produtos. } \\
\text { Negociação. }\end{array}$ \\
\hline \multicolumn{2}{|c|}{$\begin{array}{l}\text { Formatos de rua } \\
\qquad \text { (feira) }\end{array}$} & Semanal. FLV. & & $\begin{array}{l}\text { Preço baixo. Proxi- } \\
\text { midade. Qualidade } \\
\text { (produtos frescos), } \\
\text { entretenimento. }\end{array}$ \\
\hline \multirow{3}{*}{$\begin{array}{l}\text { Espe- } \\
\text { cialistas }\end{array}$} & Padarias & $\begin{array}{l}\text { Básico perecível (pão). } \\
\text { Diária ou semanal. }\end{array}$ & Preço alto. & $\begin{array}{l}\text { Qualidade. Limpeza } \\
\text { e aparência. Proxi- } \\
\text { midade. }\end{array}$ \\
\hline & Açougues & Carne & & Proximidade. \\
\hline & Sacolões & FLV & & $\begin{array}{l}\text { Preço baixo. Quali- } \\
\text { dade. }\end{array}$ \\
\hline
\end{tabular}

Quadro 4: Resumo dos atributos mais citados pelas entrevistadas de baixa renda por formatos de lojas de alimentos.

Fonte: Elaborado pelos autores.

Para a baixa renda, os locais com mais destaque são os pequenos supermercados, o atacado e a feira. Os primeiros, pela proximidade e preço baixo. A feira, pelas frutas, legumes e verduras (FLVs) frescos, proximidade e entretenimento, e o atacado pelo preço baixo.

As entrevistadas consideram os formatos de grande escala como tendo preços baixos, mas pela distância, que inclui outros fatores, como a falta de meio de transporte ou de dinheiro para pagá-lo, as dificuldades de transportar as compras e a falta da oferta de serviços facilitadores de entrega fazem com que deixam de comprar nesses locais. 


\begin{tabular}{|c|c|c|c|c|}
\hline \multirow{2}{*}{\multicolumn{2}{|c|}{ Formatos }} & \multirow{2}{*}{$\begin{array}{c}\text { Característica } \\
\text { da compra }\end{array}$} & \multicolumn{2}{|c|}{ Atributos mais freqüentes } \\
\hline & & & Ônus & Bônus \\
\hline \multicolumn{2}{|c|}{ Hipermercados } & $\begin{array}{l}\text { Semanal e Mensal. } \\
\text { Todas as categorias. }\end{array}$ & Existência de fila. & $\begin{array}{l}\text { Preço baixo. Quali- } \\
\text { dade. Atendimento. } \\
\text { Variedade. Aparência. }\end{array}$ \\
\hline \multicolumn{2}{|c|}{$\begin{array}{l}\text { Supermercados } \\
\text { de bairro }\end{array}$} & $\begin{array}{l}\text { Semanal. FLV, pão e } \\
\text { básicos embalados. }\end{array}$ & Existência de fila. & $\begin{array}{l}\text { Preço baixo. Proximi- } \\
\text { dade. Atendimento. } \\
\text { Variedade. Qualidade. }\end{array}$ \\
\hline \multicolumn{2}{|c|}{ Atacados } & Mensal. & $\begin{array}{l}\text { Existência de fila. } \\
\text { Falta de sacola. }\end{array}$ & Preço baixo. \\
\hline \multicolumn{2}{|c|}{$\begin{array}{c}\text { Pequenos } \\
\text { supermercados }\end{array}$} & Carne & $\begin{array}{l}\text { Preço alto. } \mathrm{Pe}- \\
\text { quena variedade. }\end{array}$ & $\begin{array}{l}\text { Proximidade. Açougue } \\
\text { muito bom. Atendimen- } \\
\text { to bom. }\end{array}$ \\
\hline \multicolumn{2}{|c|}{ Tradicionais } & $\begin{array}{l}\text { Compra esporádica, } \\
\text { do que faltar. }\end{array}$ & Preço alto. & Proximidade. \\
\hline \multicolumn{2}{|c|}{$\begin{array}{l}\text { Formatos de rua } \\
\text { (feira) }\end{array}$} & Semanal. FLV. & $\begin{array}{l}\text { Falta de higiene. } \\
\text { Ter que carregar } \\
\text { compras. }\end{array}$ & Qualidade das FLVs. \\
\hline \multirow{3}{*}{$\begin{array}{l}\text { Especia- } \\
\text { listas }\end{array}$} & Padarias & Diária. Pão e frios. & Preço alto. & $\begin{array}{l}\text { Qualidade. Atendi- } \\
\text { mento. Proximidade. } \\
\text { Aparência. }\end{array}$ \\
\hline & Açougues & & & Proximidade. \\
\hline & Sacolões & Preço alto. & & Qualidade. \\
\hline
\end{tabular}

Quadro 5: Resumo dos atributos mais citados pelas entrevistadas de alta renda por formatos de lojas de alimentos.

Fonte: Elaborado pelos autores.

A classe alta, por sua vez, dá preferência a formatos de larga escala, nos quais se destacam os hipermercados e supermercados, que têm o preço baixo percebido, a qualidade e a variedade de que precisam. Os formatos menores são menos freqüentados, com exceção da padaria, que é valorizada pela qualidade e proximidade.

A preferência da classe alta entrevistada pelos formatos maiores reside na maior facilidade dessa classe em se locomover e, assim, diminuir o tempo de viagem e as adversidades existentes no trajeto.

Essa percepção de preço baixo dos varejos de grande escala, entre as entrevistadas, é explicada pela observação do mercado, em que a pressão exercida pelos pequenos varejos sobre os grandes ocasionou uma diminuição dos preços ao consumidor por parte das grandes redes (FARINA; NUNES; MONTEIRO, 2004; MONTEIRO, 2005), embora, ainda, segundo os autores, não o suficiente para que o consumidor deixe de levar em conta outros fatores, como a conveniência da proximidade, que, para a alta renda, pode ser entendida como conveniência, mas para a baixa é uma necessidade. 
Nos hipermercados, as consumidoras de baixa renda entrevistadas percebem como bônus a presença de mais seções, como a de padaria e de outras que não sejam de alimentos e como ônus a diferença entre o preço da gôndola e o registrado no caixa ou cupom fiscal, a mudança de produtos de lugar e a oferta de marcas próprias.

As consumidoras de alta renda entrevistadas neste estudo fizeram críticas graves a respeito da confiabilidade e empatia, duas dimensões do serviço segundo proposta de Parasuraman et al. (1990), proporcionadas pelos hipermercados. Como problemas de confiabilidade têm-se: a presença de produtos estragados e vencidos; crença de que algumas lojas enganam os clientes com as promoções, por diminuírem o preço de alguns produtos, mas aumentarem o de outros; e colocação de preços trocados. De empatia, tem-se a pesagem no momento de checkout.

Serviços facilitadores são, conforme Grönroos (1995), observados e demandados pelas entrevistadas, como estacionamentos amplos e cobertos, empacotadores e carregadores, lojas anexas (lanchonete, caixa-automático, lotérica e pet-shop), locais para deixar as crianças, banheiro público e ar-condicionado.

As consumidoras de alta renda entrevistadas neste estudo ainda percebem como ônus questões relacionadas ao valor de eficiência (HOLBROOK, 1999), como a falta de marcas intermediárias entre as próprias e as líderes e a demanda por produtos mais finos (luxos). A questão de valor de excelência também é levantada por elas ao considerarem o açougue ruim, além de falarem a respeito do dia de promoções de FLV, que é citado tanto como um bônus quanto como um ônus.

Nos supermercados de bairro as entrevistadas de baixa renda percebem uma redução do esforço monetário pela oferta de formas de pagamento, como o cartão do estabelecimento e o vale-refeição. Serviços facilitadores, como entrega e a presença de estacionamento também são valorizados. Sob a ótica do grupo entrevistado, o fato de o supermercado ser tradicional na cidade cria uma identidade entre o consumidor e a empresa. A melhor disposição das mercadorias nas gôndolas foi citada como facilitadora para uma compra mais rápida, e a dimensão de aspectos tangíveis (PARASURAMAN et al., 1990) também foi salientada na valorização dos funcionários uniformizados. Como ônus foram citados a mudança dos produtos de local, a propaganda enganosa (dimensão de confiabilidade), o fim de semana cheio e o mau funcionamento da máquina de cartão (dimensão de tangíveis).

A classe alta compradora em supermercados de bairro valoriza o valor de entretenimento proporcionado pela música ao vivo (pianistas aos sábados) e café da manhã. O serviço facilitador de estacionamentos espaçosos e cobertos é demandado, juntamente com a questão de seguranças durante o período noturno. A troca de produtos estragados é valorizada e passa confiança, mas, por outro lado, o preço trocado dos produtos nesses locais a diminui. A promoção de FLV (Quinta verde) é considerada um bônus pelos preços baixos oferecidos, mas um ônus pelos problemas causados. 
O estacionamento e a troca de mercadorias foram considerados pela baixa renda bônus dos atacados, ao contrário da falta de empacotadores e da mudança das mercadorias de local.

Para a alta renda, o atacado possui ônus proporcionados pela falta de ar-condicionado e, novamente, problemas de confiabilidade, exemplificados pela desconfiança dos funcionários nos clientes, ao conferirem as mercadorias na saída, e pela promoção de produtos que estão vencendo. A mudança dos produtos de prateleira também é citada. A vantagem percebida por essa classe é a redução do esforço monetário por meio do desconto para grandes quantidades (compra de atacado).

Os pequenos supermercados oferecem para a baixa renda serviços relacionados à dimensão de empatia, propostos por Parasuraman et al. (1990), como os serviços facilitadores de entrega em casa sem limite mínimo de valor da compra, local para guardar bicicletas e a possibilidade de efetuar a compra pelo telefone. A dimensão de confiança tem seu lado positivo na carne vendida, mas negativo no preço da gôndola, em alguns casos, ser diferente do caixa.

Para a alta renda, o formato de pequeno supermercado tem como ônus a falta de banheiro público e o não funcionamento em finais de semana, além da questão de visual merchandising ruim relatado na aparência dos produtos na prateleira passarem um aspecto de envelhecimento. Como bônus desses locais foram citados a presença de estacionamento, comodidade, promoção na TV, ser uma empresa familiar, possuir convênio com empresa onde clientes trabalham e a troca de produtos.

Como problemas percebidos pela baixa renda em relação aos formatos tradicionais, apresentam-se a não aceitação de cartões e a má distribuição dos produtos. Como bônus tem-se o pagamento posterior ("compra fiado"), o serviço facilitador de entrega em domicílio e a troca de produtos estragados.

Como ônus dos tradicionais, a alta renda percebe o tamanho pequeno e o preço alto e, como vantagens, a proximidade e a conveniência.

Os especialistas (padaria, açougue e sacolão) têm como ônus para a baixa renda o tamanho e a validade curta de produtos (frios) e como destaque a qualidade, preço baixo da carne, conveniência e proximidade.

A alta renda percebe benefícios dos especialistas como disponibilidade para compras de emergências e alguns serviços facilitadores, como o pedido pelo telefone e a entrega em domicílio. Como ônus tem-se o fato de não estar sempre aberto.

\section{CONSIDERAÇÕES FINAIS}

Este trabalho se propôs a compreender melhor os ônus e bônus que levam consumidoras a escolher um determinado local para efetuar suas compras de alimentos $\mathrm{e}$, para tanto, buscou-se responder à pergunta numa pesquisa exploratória: quais os 
ônus e bônus que levam os consumidores a escolherem um determinado formato de loja para realizarem suas compras de alimentos?

Os diversos formatos varejistas apresentam peculiaridades, sendo que as consumidoras se valem desses atributos positivos e negativos para realizar suas escolhas. Muitas dessas escolhas estão pautadas também nas características socioeconômicas e nos recursos disponíveis às pessoas para que consigam ter acesso aos tipos de loja.

Como limitações há o fato de a pesquisa ter sido realizada somente na cidade de Campo Grande-MS.

Como contribuições empresariais podem ser citados os diversos atributos que surgiram ao longo deste trabalho, os quais devem ser levados em consideração pelas empresas que vendem alimentos, além dos diversos fatores que caracterizam as lojas e poderiam vir a ser utilizados como fatores de diferenciação para a estratégia dos formatos (MITCHELL; HARRIS, 2005).

Como contribuições acadêmicas tem-se: subsídios para a classificação dos diversos riscos e esforços apontados pelas consumidoras quando buscam comprar alimentos tanto para a baixa renda quanto para a alta, que ainda não estão presentes na literatura analisada, bem como algumas sugestões de pesquisa que surgiram a partir deste trabalho.

Como sugestões tem-se: (a) um estudo descritivo poderia ser feito para determinar as características das compras mais comuns por cada tipo de loja, como em estudo realizado por Kenhove et al. (1999); (b) trabalhos semelhantes poderiam ser realizados em outras localidades, com maior ou menor concentração urbana e desigualdade social para medir os efeitos do tempo de viagem; (c) poderia ser realizado um estudo com donas-de-casa que tenham níveis mais baixos de escolaridade do que o recorte desta pesquisa. Persiste também a possibilidade de entrevistar consumidoras das classes D e E, apenas, para saber mais sobre seus ônus e bônus percebidos; (d) uma escala para a mensuração de riscos percebidos e esforços não-monetários na compra de alimentos pode ser feita com base nas variáveis encontradas e categorizadas; e (e) a questão da feira como local de compra e de entretenimento para a baixa renda merece ser aprofundada, principalmente devido ao fato de ser um formato presente na realidade brasileira e que é pouco estudado no país.

\title{
CONSUMERS PERCEIVED VALUE: AN EXPLORATORY STUDY ABOUT THE STORES WHERE THEY DO FOODS SHOPPING.
}

\begin{abstract}
In Brazil, big food retails are losing space to small formats like, among others, small supermarkets, street formats, and bakeries. The consumers try to do their shopping in
\end{abstract}


places where the onus is decreased and the bonus is increased. To this phenomenon comprehension, the following research problem was presented: what are the onus and bonus that consumers perceive in the choice of a kind of store format to do theirs foods shopping? A knowledge review about perceived value and its antecedents was done. Then an exploratory research with in-depth interviews was done with 51 households ( 26 of low income and 25 of high income) was conducted in a medium Brazilian city. The results showed that the consumer's mainly preoccupation was with the issues of price and travel time (proximity). The Holbrook's (1999) values were also analyzed, as well as efforts and perceived risks. In the work's conclusion limitations and suggestions for new researches are presented.

Keywords: Consumer Behavior. Perceived Value. Perceived Sacrifice. Perceived Risk. Food Retail Attributes.

\section{REFERÊNCIAS}

AGARWAL, Sanjeev; TEAS, R. Kenneth. Perceived value: Mediating role of perceived risk. Journal of Marketing Theory and Practice, Statesboro, v. 9, I. 4, p. 1-14, Fall 2001.

BAUER, Raymond A. Consumer Behavior as Risk Taking, in Dynamics Marketing for a Changing World, Robert S. Hancock, ed., Chicago: American Marketing Association, p. 389-398, 1960.

BENDER, Wesley C. Consumer Purchase-Costs - Do Retailers Recognize Them? Journal of Retailing, v. 40, I. 1, p. 1-9, Spring 1964.

BERRY, Leonard L. The Time Buying Consumer. Journal of Retailing, v. 55, I. 4, p. 58-70, Winter 1979 .

BISCOLA, Paulo. H. N. Valor Percebido pelo Consumidor: Um estudo exploratório em relação às lojas onde realiza compras de alimentos. 2005. 155p. Dissertação (Mestrado em Administração de Empresas) - Escola de Administração de Empresas de São Paulo da Fundação Getúlio Vargas, São Paulo, 2005.

BLOOM, D. Top ideas for supermarkets. Progressive Grocer, v. 84, I. 7, p. 140. $5 / 1 / 2005$.

BOOZ ALLEN HAMILTON. Creating Value in Retailing for Emerging Consumers: Breaking Myths about Emerging Consumers - Learning from Small Scale Retailers. 
An Exploratory Study conducted for the Coca-Cola Retail Research Center - Latin America, jun. 2003. Disponível em: $<$ http://www.coke.net/home/portal/.cmd/ActionDispatcher/_pagr/109/_pa.109/135/.aref/1857406929/.md/-/.piid/414/.ciid/752\#1>. Acesso em: 9 mai. 2005.

CAMPBELL, Margaret C.; GOODSTEIN, Ronald C. The Moderating Effect of Perceived Risk on Consumers' Evaluations of Product Incongruity: Preference for the Norm. Journal of Consumer Research, v. 28, I. 3, p. 439-450, Dec. 2001.

CHERLOW, Jay. Measuring Values of Travel Time Savings. Journal of Consumer Research, v. 7, p. 360-371, 1981.

CHURCHILL, G. A., Jr. Marketing Research: methodological foundations. 6th ed. New York: Dryden Press, 1995.

CONCHAR, M.; ZINKHAN, G. M.; PETERS, C.; OLAVARRIETA, S. An Integrated Framework for the Conceptualization of Consumers` Perceived-Risk Processing. Journal of the Academy of Marketing Science, v. 32, I. 4, p. 418-436, Fall 2004.

CONSUMIDOR dá o perfil da loja ideal. Superhiper, set. 2004.

CORREA, Cristiane. Compadre do varejo. Exame, dez. 2003.

DODDS, W. B.; MONROE, K. B.; GREWAL, D. Effects of price, brand, and store information on buyer's product evaluations. Journal of Marketing Research, $\mathrm{v}$. 28, I. 3, p. 307-314, Aug. 1991.

DOWNS, A. A Theory of Consumer Efficiency. Journal of Retailing, v. 37, Spring 1961.

FARINA, E. M. M. Q.; NUNES, R.; MONTEIRO, G. F. A. Supermarkets and their Impacts on the Agrifood System of Brazil: the competition among retailers. In: 14th ANNUAL WORLD FOOD \& AGRIBUSINESS SYMPOSIUM, 2004, Montreux. Disponível em: $<$ http://www.ifama.org/conferences/2004Conference/Papers/Farina1059.pdf>. Acesso em: 4 dez. 2005, 22:15. IAMA, 2004.

FLINT, D. J.; WOODRUFF, R. B.; GARDIAL, S. F. Customer Value Change in Industrial Marketing Relationships: a call for new strategies and research. Industrial Marketing Management, v. 26, I. 2, p. 163-175, Mar. 1997. 
FOX, Karen F. A. Time as a Component of Price in Social Marketing, in Marketing in the 1980s, R. P. BAGOZZI et al., eds., Chicago: American Marketing Association, 464-467, 1980.

FOX E. J.; MONTGOMERY, A. L.; LODISH, L. M. Consumer shopping and spending across retail formats. Journal of Business, v. 77, I. 2, p. S25-S60, Apr. 2004.

GREWAL, D.; BAKER, J. LEVY, M.; VOSS, G. B. The effects of wait expectations and store atmosphere evaluations on patronage intentions in service-intensive retail stores. Journal of Retailing, v. 79, I. 4, p. 259-269, Winter 2003.

GRÖNROOS, Christian. Marketing, gerenciamento e serviços: a competição por serviços na hora da verdade. Rio de Janeiro: Campus, 1995.

HEINONEN, Kristina. Time and Location as Customer Perceived Value Drivers. Helsingfors: Publications of the Swedish School of Economics and Business Administration, 2004. Disponível em: $<$ http://shh.fi/services/ biblio/papers/fulltextes/124-951-555-818-2.pdf>. Acesso em: 29 ago. 2005, 18:10.

HOLBROOK, M. B. Consumer value: a framework for analysis and research. London: Routledge, 1999.

HORTON, Raymond L. The structure of Perceived Risk. Journal of the Academy of Marketing Science, v. 4, n. 4, p. 694-706, 1976.

JACOBY, Jacob; KAPLAN, Leon B. The Components of Perceived Risk, in Proceedings of the 3rd Annual Conference of the Association for Consumer Research, M. Venkatesan, ed., p. 382 - 393. 1972.

JARRAT, D. G. Outshopping behaviour: an explanation of behaviour by shopper segment using structural equation modelling. International Review of Retail, Distribution and Consumer Research, v. 10, I. 3, p. 287-304, Jul. 2000.

KENHOVE P. V.; WATERSCHOOT, W. V.; WULF, K. The impact of task definition on store choice and store-attribute saliences. Journal of Retailing, v. 75, I.1, p. 8-10, Spring 1999.

LIMA FILHO, Dario de Oliveira. Valor Percebido e o Comportamento do Consumidor de Supermercado: um estudo exploratório em uma média cidade brasileira. 1999. 196p. Tese (Doutorado em Administração de Empresas) - Escola de Administração de Empresas de São Paulo da Fundação Getúlio Vargas, São Paulo, 1999. 
MALHOTRA, Naresh K. Pesquisa de marketing: uma orientação aplicada. 3. ed. Porto Alegre: Bookman, 2002.

MITCHELL, V.; HARRIS, G. The importance of consumers` perceived risk in retail strategy. European Journal of Marketing, v. 39, I. 7/8, p. 821-837. 2005.

MONROE, K. B.; KRISHNAN, R. The effect of price on subjective product evaluations. In Perceived Quality - how consumers view stores and merchandise. Lexington: Lexington Books, p. 209 - 232, 1985.

MONROE, K. B. Pricing: Making Profitable Decisions. McGraw-Hill, New York, NY, 1991.

MONTEIRO, G. F. A. Is the Traditional Retailing disappearing? Some evidences from Brazil. In: 15th ANNUAL WORLD FOOD \& AGRIBUSINESS SYMPOSIUM, 2005, Chicago. Disponível em: http://www.ifama.org/ conferences/2005Conference/Papers\&Discussions/ 1082_Paper_Final.pdf. Acesso: 04/12/05, 22:10. IAMA, 2005.

MOURA, Thais Lacava de. Formatos de varejo de alimentos: um estudo sobre as preferências do consumidor. 2005. 210p. Dissertação (Mestrado em Engenharia de Produção) - Universidade Federal de São Carlos, São Carlos, 2005.

MURPHY, P. E.; ENIS, B. M. Classifying products strategically. Journal of Marketing, v. 50, p. 24-42, Jul. 1986.

PARASURAMAN, A.; BERRY, Leonard L.; ZEITHAML Valarie A. Delivering Quality Service: balancing customer perceptions and expectations. New York: The Free Press, 1990.

PESQUISA exclusiva mostra. Superhiper, mar. 2003.

PRAHALAD, C. K. The Fortune at the Bottom of the Pyramid. New Jersey: Wharton School Publishing, 2005.

RAVALD, Annika; GRÖNROOS, Christian. The Value Concept and Relationship Marketing. European Journal of Marketing, v. 30, I. 2, p. 19-30, 1996.

ROSELIUS, T. Consumer ranking of risk reduction methods. Journal of Marketing, v. 35, p. 56-61, 1971. 
SAMLI, A. C.; UHR, E. B. The outshopping spectrum: key for analyzing intermarket leakages. Journal of Retailing, v. 50, I. 2, p. 70-80, Summer 1974.

SANTOS, Rubens da C. Oferecendo valor para o cliente. Marketing Industrial, s. v., n. 7, p. 31-57, 1997.

SHETH, Jagdish N.; GARDNER, David M. e GARRETT, Dennis E. Marketing Theory: Evolution and Evaluation. John Wiley \& Sons, 1988.

SINHA, I.; DeSARBO, W. An Integrated Approach Toward the Spatial Modeling of Perceived Customer Value. Journal of Marketing Research, v. 35, I. 2, p. 236-249, May 1998.

SLATER, S. F.; NARVER, J. C. Intelligence Generation and Superior Customer Value. Journal of the Academy of Marketing Science, v. 28, I. 1, p. 120-128, Winter 2000.

SNOJ, Boris; KORDA, Aleksandra Pisnik; MUMEL, Damijan. The relationships among perceived quality, perceived risk and perceived product value. Journal of Product \& Brand Management, v. 13 I. 3, p. 156-167, 2004.

STONE, Robert; GRONHAUG, Kjell. Perceived Risk: Further Considerations for the Marketing Discipline. European Journal of Marketing, v. 27, I. 3, p. 39-50, 1993.

SUPERMERCADOS querem aumentar a fidelidade dos consumidores. Gazeta Mercantil, São Paulo, 6 de maio 2005.

SWEENEY, Jillian C.; SOUTAR, Geoffrey N.; JOHNSON, Lester W. The Role of Perceived Risk in the Quality-Value Relationship: A Study in a Retail Environment. Journal of Retailing, v. 75, I. 1, p. 77-105, 1999.

TEAS, R. Kenneth; AGARWAL, Sanjeev. The Effects of Extrinsic Product Cues on Consumers' Perceptions of Quality, Sacrifice, and Value. Journal of the Academy of Marketing Science, v. 28, I. 2, p. 278-290, Spring 2000.

THANG, D. C. L.; TAN, B. L. B. Linking consumer perception to preference of retail stores: an empirical assessment of the multi-attributes of store image. Journal of Retailing and Consumer Services, v. 10, I. 4, p. 193-201, Jul. 2003.

URDAN, A. T.; ZUÑIGA, K. H. O consumidor recompensa o comportamento ético empresarial? In: $25^{\circ}$ ENCONTRO ANUAL DA ANPAD, 2001, Campinas. Anais do $25^{\circ}$ ENCONTRO ANUAL DA ANPAD, 2001. CD-ROM. 
Valor percebido pelos consumidores: um estudo exploratório em relação às lojas onde realizam compras de alimentos

WOODRUFF, R. B. Customer Value: The Next Source for Competitive Advantage. Journal of the Academy of Marketing Science, v. 25, I. 2, p. 139-154, Spring 1997.

ZEITHAML, Valerie A. Consumer Perceptions of Price, Quality and Value: A meansend model and synthesis. Journal of Marketing, v. 52, p. 2-22, Jul. 1988. 